\title{
Induction of nest-material collecting in male Barbary doves by intracerebral androgen
}

\author{
C. J. Erickson* and J. B. Hutchison \\ M.R.C. Unit on the Development and Integration of Behaviour, \\ Madingley, Cambridge CB3 $8 A A, U . K$.
}

\begin{abstract}
Summary. The behaviour of the male Barbary dove (Streptopelia risoria) in selecting nesting material and transporting it to the nest site is reduced after castration and is restored by treatment with testosterone propionate when castrated males received unilateral intracerebral implants of this androgen. Implants in the anterior hypothalamus, preoptic region, and the area of the ventral neostriatum intermediale were effective in reinstating the collection of nesting material, and in many instances restoration of the behaviour was to levels at or above those observed before castration. Implants in other areas, and implants without hormone, were generally without effect. Although the brain areas from which the gathering of nesting material can be elicited are comparable to those from which courtship displays have been induced in previous studies, it appears that testosterone propionate implants stimulate nesting activities more effectively and more persistently than courtship.
\end{abstract}

\section{Introduction}

In the Barbary dove (Streptopelia risoria) the male selects the nesting material and transports it to the nest site; the female then fashions it into a nest. During the normal breeding cycle nest construction does not begin until the partners have spent several days in active courtship, and males rarely gather nesting material until provided with the stimulus of a female at the nest site. The attachment of the female to the nest site and her readiness to engage in nest-building activity reflect the influence of ovarian hormones which are secreted as a result of exposure to male courtship (Erickson, 1970; Korenbrot, Schomberg \& Erickson, 1974; Silver, Reboulleau, Lehrman \& Feder, 1974). By contrast, sexually active males are physiologically ready to gather nesting material when introduced to the female or shortly thereafter, as shown by introduction of males to females that have been previously treated with oestradiol and progesterone (Martinez-Vargas \& Erickson, 1973). Castrated males, however, do not respond to treated females unless they are themselves treated with an oestrogen or an androgen (Martinez-Vargas, 1974). The collection of nesting material by the male is therefore dependent both upon his gonadal hormones and the stimuli associated with a female that has become established at the nest site.

Although it is established that localized brain implants of testosterone propionate can induce male courtship display, aggressive behaviour (Hutchison, 1967, 1970b, 1971; Barfield, 1971) and copulation (Barfield, 1971) in castrated male doves, it is not known whether male participation in nest building can be similarly induced. If nest material collection can be so induced, it would be of considerable interest to determine whether the loci from which the behaviour can be elicited are similar or dissimilar to those involving other behaviour patterns. Moreover, if the gathering of nesting material and its transport to the nest site can be stimulated by intracerebral implantation of androgen in castrated males, it is important to determine whether this behaviour pattern follows the circadian rhythm described by Martinez-Vargas \& Erickson (1973). If castrated males with androgen implants retain the normal activity in late morning and early afternoon, it would indicate that the rhythms of intact males during normal breeding are independent of daily fluctuations in testicular hormone secretion.

* Present address: Department of Psychology, Duke University, Durham, North Carolina 27706, U.S.A. 


\section{Materials and Methods}

None of the adult Barbary doves (Streptopelia risoria) used had had previous breeding experience or any opportunity to construct a nest.

The birds were housed in a single large outdoor cage for 1 year. Before the experiment the birds were subjected to laparotomy to determine their sex. They were then placed in indoor cages $(60 \times 40$ $\times 40 \mathrm{~cm}$ ) and maintained for 1-5 months in visual, but not auditory, isolation from other doves. Each cage was provided with a perch, and food and water were always available. During this period and throughout the remainder of the study the birds received $14 \mathrm{~h} \mathrm{light} /$ day between 08.00 and $22.00 \mathrm{~h}$.

\section{General procedure of observation and testing}

Twenty-three males were observed for nest-building activity before castration, following castration, and after receiving an intracerebral implant. During these tests males were taken from their isolation cage and placed with the stimulus females in cages which differed only slightly from those used by Martinez-Vargas \& Erickson (1973). All test cages were $67 \mathrm{~cm}$ high, $95 \mathrm{~cm}$ wide, and $103 \mathrm{~cm}$ deep and were fitted with a perch and a low partition $25 \mathrm{~cm}$ high which divided the floor area. Food and water were always available. During testing, each cage was provided with a nest receptacle. This consisted of a low square pan $(18 \times 18 \mathrm{~cm})$ of sheet metal $10 \mathrm{~cm}$ deep. Within this pan was slung a smaller pan $(15 \times 15 \mathrm{~cm}, 8.5 \mathrm{~cm}$ deep) of plastic-coated, $1-\mathrm{cm}$ hardware cloth so that it was separated from the walls of the outer pan by a space of $1.5 \mathrm{~cm}$ all around. This construction was effective in ensuring that any nesting material tucked into the nest by the female became firmly lodged between the inner lining of wire mesh and the outer pan. Consequently, little of the nesting material fell from the nest once it was delivered by the male.

The nesting material consisted of No. 2 split cane of the type used in furniture construction. This material has the advantage of high flexibility and resistance to kinking and breaking: it could therefore be used repeatedly without loss of quality. A large supply of this cane in $15 \mathrm{~cm}$ lengths was available from two metal slings attached to the inside of the cage.

Stimulus females. Stimulus females were prepared as described by Martinez-Vargas \& Erickson (1973): i.m. injections of $200 \mu$ g oestradiol benzoate and $100 \mu \mathrm{g}$ progesterone were given each day for a minimum of 14 days before testing. Because of the difficulty of ovariectomy and because MartinezVargas \& Erickson (1973) had found that intact hormone-treated females provided effective stimuli for nest material collection by males, the ovaries were not removed from stimulus females in the present experiment. Martinez-Vargas (1974) reported, however, that females were sometimes less responsive to the hormones when paired with untreated castrated males than with steroid-treated males. To ensure that females provided an optimal stimulus to males under the conditions of the present investigation, several precautions were taken. For 3 weeks before use in the study all females were given daily injections of oestradiol benzoate and progesterone. They were then allowed a week of nest-building experience with normal intact males in the test cages. During the intervals between testing, the females were allowed to reside in the test cages, and each female was observed throughout all phases of testing with a male. Test cages were inspected each hour of the day from $10.30 \mathrm{~h}$ to $19.30 \mathrm{~h}$. The location of the male and female was noted, and any engagement in nest construction was recorded. These checks also established that the females had become attached at the nest site and that the nesting material was collected by the males and not by the females. The hourly inspections were reinforced during the postimplantation tests by continuous 60 -min observation when nest building was most active (11.30-12.30 h).

Precastration tests. Before testing, the nest receptacle was placed in the cage and a supply of nesting material was deposited in the dispensers. At approximately $09.00 \mathrm{~h}$ the male was placed in the test cage containing the stimulus female. Except when removed for a 3-min courtship test on the 2nd day, the male remained with the female for $48 \mathrm{~h}$. The courtship results will be reported elsewhere.

All nesting material that had been carried across the centre partition was tallied on the second morning, approximately $24 \mathrm{~h}$ after introduction of the male to the test cage. The count included all 
nesting material found in the nest pan as well as any on the floor below. The latter typically amounted to $3 \%$ or less of the total. Since males usually returned fallen material to the nest pan, the nest material counts are a conservative index of male gathering activity. After the nesting material was counted it was returned to the dispenser. A second count was made on the morning of the $3 \mathrm{rd}$ day when the birds had been together for $48 \mathrm{~h}$. The male was then returned to isolation.

Postcastration tests. All males were tested for nest-building performance 4 weeks after castration. The procedure was identical to that for the precastration tests. Because $48 \%$ of the males continued to exhibit considerable gathering activity at this time, all males were given a second series of postcastration tests at 6-8 weeks after gonadectomy.

Postimplantation tests. Males received intracerebral implants 2 weeks after the second postcastration test series. After 3 days in isolation to recover from the surgery, the males were placed in the test cages with stimulus females and their nest-material gathering performances were examined over a period of 10 consecutive days. (Four of the 12 males with implants in the anterior hypothalamuspreoptic region were an exception. In these testing was postponed for 1 week after surgery to examine courtship responses without interference from the tests for nest building. There were no systematic differences in the nest-building behaviour of these males when compared to that of others bearing similar hormone implants. The effects of the implants on courtship will be the subject of another report.) Except for the longer testing interval, the procedures for examining nest building in the postimplantation period were similar to those for precastration and postcastration testing. On the 4th day of postimplantation testing, however, each male was allocated to another stimulus female and remained with her until the end of the 10-day test period. The purpose of this single rotation was to determine whether characteristic collection patterns established within the first 3 days would persist when the male was placed with another stimulus animal. If collection scores remained constant for individual males, it would provide further evidence that any individual differences in gathering activity among males were primarily a manifestation of the internal state of these birds rather than a reflection of differing stimulus conditions.

\section{Surgical and histological procedures}

The surgical procedures used in castrating male Barbary doves have been described in detail previously (Hutchison, 1970a), as have those used in preparing the fused crystalline testosterone propionate implants on 33-gauge stainless-steel probes and in positioning the probes unilaterally in the brain (Hutchison, 1971). The amount of hormone in each spherical implant is shown in Text-fig. 1.

The brain of each male was sectioned transversely $(20 \mu \mathrm{m})$ after fixation in Bodian fixative and was stained using the luxol fast blue-cresylecht violet stain of Kluver \& Barrera (1953). The relevant sections showing the needle tract were compared with a standard set of transverse sections cut in this plane, using the nuclei, the major fibre tracts and ventricles as frames of reference to establish the position of the implant.

An autopsy was performed to determine whether testicular regeneration had occurred. The vasa deferentia and epididymides were removed, fixed in Bouin's solution, and weighed.

\section{Results}

All males exhibited a reduction in nest-building behaviour after castration, but for most a low level of activity was not achieved until the second postcastration test series. Four of the 23 males, however, continued to gather substantial amounts of nest-building material even at 6-8 weeks after surgery. Autopsy revealed that castration was complete in these and all the other males.

Courtship behaviour has previously been shown to be most responsive to androgen implants in the preoptic and anterior hypothalamic regions (Hutchison, 1967; Barfield, 1971). The present study indicated that the collection of nesting material is also promoted by testosterone propionate in these areas of the brain (Text-figs 1 and 2). Histological examination showed that 12 males had received testosterone propionate in these regions. Because males were tested for only 2 postcastration days 

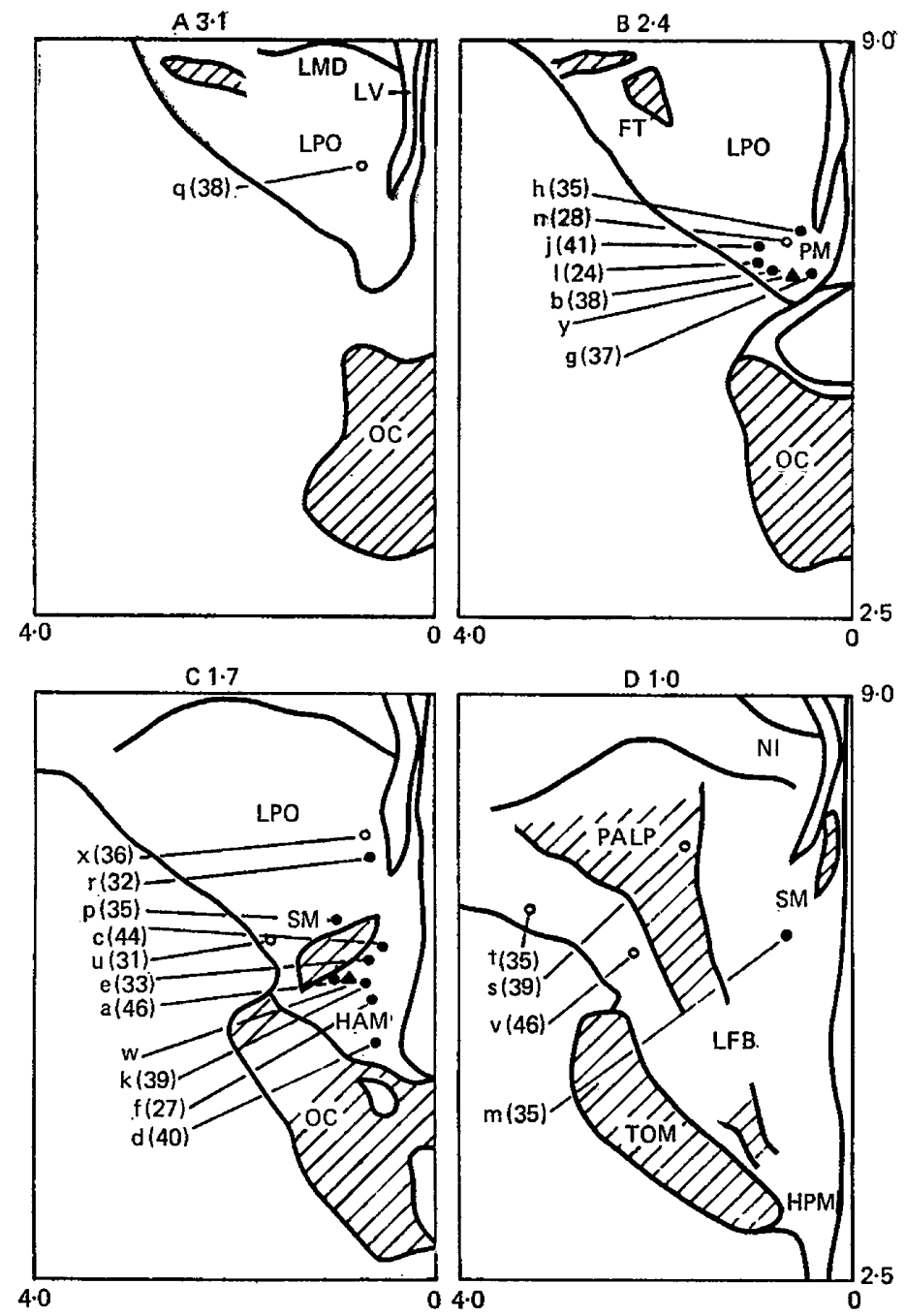

Text-fig. 1. Location of implants of testosterone propionate in the brains of male Barbary doves. The weight $(\mu \mathrm{g})$ of hormone applied to each probe is given in parentheses. The stereotaxic co-ordinates and the orientation of the transverse sections correspond to those detailed by Hutchison (1971). FT, tractus frontothalamicus; HAM, nucleus hypothalamicus anterior medialis; HPM, nucleus hypothalamicus posterior medialis; LFB, lateral forebrain bundle; LMD, lamina medullaris dorsalis; LPO, lobus parolfactorius; LV, lateral forebrain ventricle; NI, neostriatum intermediale; OC, optic chiasma; PALP, paleostriatum primitivum; PM, nucleus preopticus medialis; SM, septomesencephalic tract; TOM, tractus opticus marginalis. - implants in males that more than doubled their postcastration levels of collection and gathered at least 40 cane strips during the first 2 postimpiantation test days. 0 , implants in males that exhibited no increase in collection or gathered $<20$ cane strips during the first 2 postimplantation days. $\Delta$, blank implants (see text for explanation).

at a time, the most appropriate period for comparing the effects of implantation was the first 2 days of postimplantation testing. Among the 12 males with preoptic or anterior hypothalamic implants of testosterone propionate there was a marked elevation in the collection of nesting material on the first 2 postimplantation test days when compared with the performance levels of the same males during the second 2-day postcastration tests (Wilcoxon matched-pairs signed-ranks test; two-tailed; $t=2 ; P<0 \cdot 01$ ). Moreover, nest-material collection among these males was significantly greater 


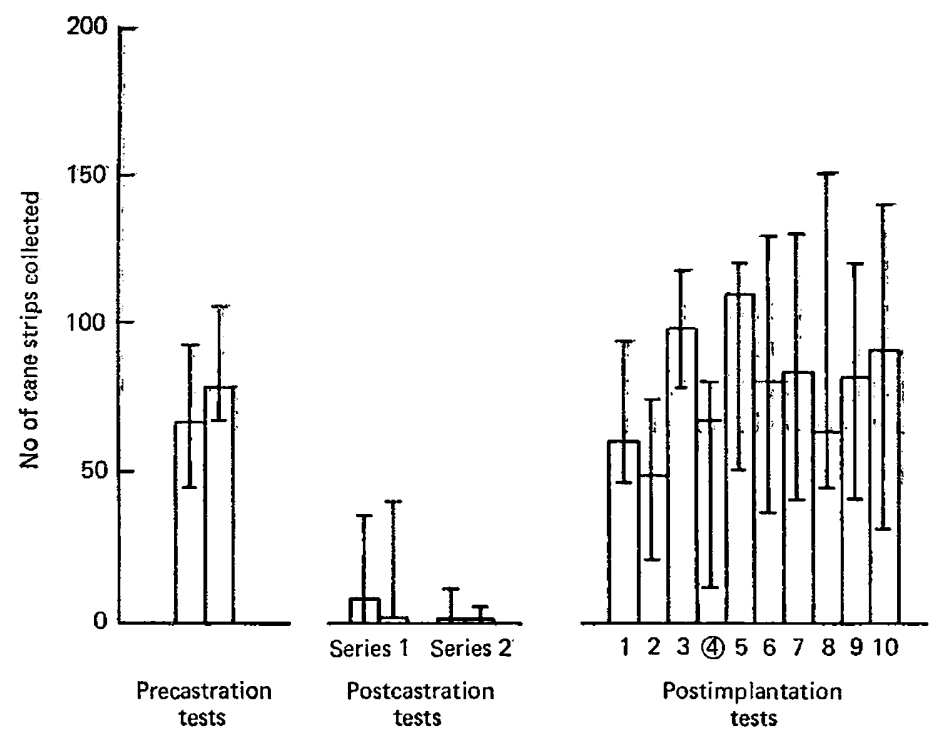

Text-fig. 2. Nest-material collection by 12 male Barbary doves with implants of testosterone propionate in the anterior hypothalamus or preoptic region. The columns and bars represent the median number and interquartile range of cane strips gathered by these males before castration ( 2 tests on successive days), after castration ( 4 tests, 2 each at 4 weeks and at 6-8 weeks) and after receiving an implant of testosterone propionate. Rotation of stimulus conditions (see text) occurred on Day 4 of the postimplantation tests.

when compared as a group to the postimplantation performances of the 9 other males receiving implants of testosterone propionate (Mann-Whitney $U$ test; two-tailed; $U=3 ; P<0.002$ ). This activity continued at a high level throughout the 10-day postimplantation test period, and it approximated precastration levels. Although most of the males collected no nesting material during the second 2-day series of postcastration tests, all gathered at least 46 cane strips during the first 2 days after insertion of the implants. For example, Male $c$, the most responsive animal, gathered no material after castration but brought 228 strips to the nest site during the first 2 days of postimplantation testing. Male $n$ was the only individual with testosterone propionate implanted in this region that did not provide a clear positive response; although a large amount of nesting material was collected after androgen implantation (149), the postcastration score (201) was unusually high.

Nine males received testosterone propionate implants in the archistriatal, paleostriatal, or neostriatal areas outside the preoptic region and anterior hypothalamus (Text-fig. 1). The group performance of these males did not differ significantly from that after castration (Wilcoxon matched-pairs signed-ranks test; two-tailed; $t=14 ; P>0 \cdot 25)$, but three males $(m, p$, and $r)$ with medial implants dorsal to the most responsive region increased their collection scores (from 26 to $57 ; 7$ to 66 ; and 8 to 63 respectively) and these have been classified as positive responses in Text-fig. 1. However, the postimplantation performance levels of these 3 males were lower than all but one of the males bearing testosterone propionate implants in the preoptic and anterior hypothalamic regions.

The hourly inspections indicated that the collection of nesting material occurred mainly during the late morning. On the 7 th day of postimplantation testing 4 active males were observed continuously from 10.30 to $13.30 \mathrm{~h}$, and all 4 collected all of the nesting material for that day during this interval, $60.5 \%$ being gathered during the period from 11.30 to $12.30 \mathrm{~h}$.

One male (Male $y$ ) that received a blank implant in the medial preoptic region exhibited no increase in collection activity. On the other hand, a second male (Male $w$ ) achieved a slightly elevated score after receiving a similar blank implant in a comparable region of the brain. However, the female associated with Male $w$ was observed to gather a few strips of cane and to add them to the nest when returning from excursions to drink or feed. The collection of nesting material by this female repre- 
sented one of two instances in the present experiment in which the stimulus female collected nesting material. The other female collected a considerable amount of material on 1 day and this behaviour was probably associated with an injection of ineffective progesterone (C. Martinez-Vargas, personal communication) as the activity ceased when the next injection was given.

A Spearman rank correlation indicated a positive but statistically insignificant relationship between the weight of the implanted hormone and the median number of strips collected by the males $\left(r_{s}=+0.24 ; P>0.05\right)$. Rotation of the males showed that the number of canestrips collected appeared to be unaffected by particular females. Correlation of the collection scores of the males with implants for the day before and the day after this rotation produced a Spearman rank correlation of $r_{s}=+0.45 ; P<0.95$. This reliability in male performance was only slightly lower than the day-to-day reliability when no rotation of stimulus females occurred. For example, the correlation of scores from Days 2 and 3 was $r_{s}=+0 \cdot 48$, and from Days 4 and 5 was $r_{s}=+0 \cdot 51$.

\section{Discussion}

Intracerebral implantation of testosterone propionate clearly produces a marked elevation in the collection of nesting material by male Barbary doves, especially when the hormone is placed in the anterior hypothalamus and preoptic region. In general, these sites correspond well with those from which Hutchison (1970b, 1971) and Barfield (1971), using similar techniques, induced chasing, bowcooing and nest-soliciting behaviour. This is not to suggest, however, that the same neural systems are necessarily involved.

It seems unlikely that testosterone propionate was reaching peripheral structures outside the CNS, although limited diffusion may have occurred within the brain itself, because of the localization of hormone effects within the brain and the atrophy of the accessory organs in all males.

Martinez-Vargas (1974) found that oestradiol benzoate or testosterone propionate, when given systemically, could induce the collection of nesting material by male ring doves when paired with females that had been injected with oestrogen and progesterone. The present study does not resolve the issue of whether endogenous oestrogens or androgens are the most directly effective agents inducing this behaviour. The possibility remains that conversion products of testosterone, such as oestrogens, could indeed be responsible. If metabolites of testosterone propionate were effective in the present study, conversion probably took place within the CNS itself. That such conversions are possible in mammals has been shown by Naftolin, Ryan \& Petro (1972).

After castration and implantation of testosterone propionate into responsive brain areas, males continued to exhibit the circadian rhythms of nest-material collection that characterize normal nestbuilding activity (Martinez-Vargas \& Erickson, 1973), indicating that these rhythms are not dependent upon underlying patterns of testicular secretion. It is possible that the daily fluctuations found in the present study were due to gonadal rhythms in the stimulus females but this is unlikely because the females were being treated with amounts of oestradiol benzoate and progesterone large enough to override normal ovarian activity. It is most likely that these circadian rhythms refiect changes within the CNS itself and that the variations are independent of the patterns of steroid hormone secretion from the gonads.

During the postimplantation testing of Males $a, b$ and $c$ it was noticed that nest-material collection and nest construction were occurring at progressively later periods on each successive day. It was then discovered that this was associated with a failure in the clock-controlled lighting system and that these birds had been receiving continuous light. The fault was corrected after the 4th day of postimplantation testing. Comparison with the performances of other males with similar implants indicated that this did not detectably affect male display or the amount of nesting material gathered. After correction of the fault there was an immediate return to mid-day nest building. Before this adjustment it was noted that, as the nest-building behaviour drifted later into each day, each pair was drifting at a different rate and was no longer building synchronously with the other pairs in the room. Nevertheless, the male and female partners in each cage continued to synchronize their nest-building contributions with one another as before, and they progressed in their nest construction in a manner not noticeably different from that of other animals on the regular light-dark schedule. This observation 
seems to indicate that there is some social facilitatory effect that aids the male and female in synchronizing their efforts.

Although nest-material collection appears to be dependent upon gonadal steroids, the effects of castration take a long time to appear when compared to the effects of gonadectomy on courtship displays. Nest-soliciting often declines more slowly than bow-cooing following castration, but both behaviour patterns usually disappear within 3 weeks of gonadectomy (Erickson, 1970; Hutchison, 1970a). In the present study the collection of nesting material did not fall to low levels until 6-8 weeks after castration. Furthermore, testosterone propionate implants in the anterior hypothalamus and preoptic region, given more than 60 days after castration, were uniformly effective in restoring nestmaterial collection, often to levels approximating and even exceeding precastration performance. Similar implants seldom result in the return of the bow-cooing display to former levels (Hutchison, $1970 \mathrm{~b}, 1971$ ), and the effectiveness of such implants declines when the interval between castration and implantation exceeds 60 days (Hutchison, 1974). Another difference between the effects of intrahypothalamic testosterone propionate implants on male courtship and on the collection of nesting material lies in the persistence of the response. Previous studies (Hutchison, 1976) indicate that all components of courtship consistently reached a peak in display 2-6 days after implantation and then declined rapidly; 8-10 days after implantation few males displayed courtship. By contrast, in the present study nest material collection reached peak levels soon after postimplantation testing began and remained at these high levels without decline throughout the subsequent days of testing. Since the weights of implants removed from the brains of castrated male doves during the period of decline in courtship response do not differ significantly from those of implants removed during the period of maximal response (J. B. Hutchison, unpublished data), the loss of hormone appears to be negligible over the period of the experiment. As suggested previously (Hutchison, 1974), the decline in courtship response may be a function of gliosis or other tissue reaction which masks diffusion of hormone from the implant. However, the lack of decline of nesting response to implants over time indicates that either the initial pulse of androgen from the implant is sufficient for prolonged activation of behaviour when there is adequate sensory stimulation, or that the masking of diffusion by a tissue reaction reduces the amount of androgen reaching the hormone-sensitive areas of the brain, perhaps to levels which are below threshold for courtship but above threshold for nesting behaviour. Confirmation of the latter conclusion would suggest a difference in sensitivity of the mechanisms underlying courtship and nesting to androgen.

Differences in responsiveness to implanted testosterone propionate among the various androgendependent behaviour patterns may represent fundamental variations in the dependence and sensitivity of the underlying neural systems to the hormone. Those systems associated with nest-material collection may be affected more easily in the absence of hormone and may require less hormone to achieve full levels of response. Such conclusions must be drawn with caution, however, since it is difficult or impossible to equate with precision the effectiveness of the stimulus conditions in the tests for nest building and courtship display.

We thank Patricia Fennell who helped with the observations, Raj Riar who performed the histological work, and Rosemary Hutchison and Bonnie Erickson who read and commented on the manuscript. This work was supported by the British Medical Research Council (J.B.H.) and Research Grant HD 04482 from the National Institute of Child Health and Human Development (C.J.E.).

\section{References}

BARFIELD, R.J. (1971) Activation of sexual and aggressive behavior by androgen implanted into the male ring dove brain. Endocrinology 89, 1470-1476.

ERICKson, C.J. (1970) Induction of ovarian activity in female ring doves by androgen treatment of castrated males. J. comp. Physiol. Psychol. 71, 210-215. HutchisoN, J.B. (1967) Initiation of courtship by hypothalamic implants of testosterone propionate in castrated doves (Streptopelia risoria). Nature, Lond. 216, 591-592. 
Hutchison, J.B. (1970a) Differential effects of testosterone and oestradiol on male courtship in Barbary doves (Streptopelia risoria). Anim. Behav. 18, 41-51.

Hưtchison, J.B. (1970b) Influence of gonadal hormones on the hypothalamic integration of courtship behaviour in the Barbary dove. J. Reprod. Fert., Suppl. 11, 15-41.

Hutchison, J.B. (1971) Effects of hypothalamic implants of gonadal steroids on courtship behaviour in Barbary doves (Streptopelia risoria). J. Endocr. 50 , 97-113.

Hutchison, J.B. (1974) Post-castration decline in behavioural responsiveness to intrahypothalamic androgen in doves. Brain Res. 81, 169-181.

Hutchison, J.B. (1976) Hypothalamic mechanisms of sexual behavior, with special reference to birds. $A d v$. Stud. Behav. 6, 159-200.

KIUVER, H. \& BARrera, E. (1953) A method for the combined staining of cells and fibers in the nervous system. J. Neuropath. exp. Neurol. 12, 401-402.
Korenbrot, C.C., Schomberg, D.W. \& Erickson, C.J. (1974) Radioimmunoassay of plasma estradiol during the breeding cycle of ring doves (Streptopelia risoria). Endocrinology 94, 1126-1132.

Martinez-VARGas, M.C. (1974) Nest building in the ring dove (Streptopelia risoria) : hormonal and social factors. Behaviour 50, 123-151.

Martinez-Vargas, M.C. \& ERICKSON, C.J. (1973) Social and hormonal determinants of nest building in the ring dove (Streptopelia risoria). Behaviour 45, 12-37.

Naftolin, F., Ryan, K. J. \& Petro, Z. (1972) Aromatization of androstenedione by the anterior hypothalamus of adult male and female rats. Endocrinology 90, 295-298.

Silver, R., Reboulleau, C., Lehrman, D.S. \& Feder, H.H. (1974) Radioimmunoassay of plasma progesterone during the reproductive cycle of male and female ring doves (Streptopelia risoria). Endocrinology 94, 1547-1554.

Received 29 May 1976 